\title{
miRNA expression pattern associated with prognosis in elderly patients with advanced OPSC and OCC
}

\author{
HENAN ZHAO $^{1 *}$, YANFANG DING ${ }^{1 *}$, BI TIE $^{2}$, ZHEN-FENG SUN $^{2}$, JI-YONG JIANG $^{2}$, \\ JINYAO ZHAO $^{1}$, XINGCHI LIN ${ }^{1}$ and SHIYING CUI ${ }^{1}$ \\ ${ }^{1}$ Dalian Medical University; ${ }^{2}$ Obstetrics and Gynecology Hospital, Dalian, P.R. China
}

Received March 15, 2013; Accepted May 2, 2013

DOI: $10.3892 /$ ijo.2013.1988

\begin{abstract}
The long-term survival for elderly patients with advanced ovarian papillary serous carcinoma (OPSC) does not exceed 30\%, and the incidence and prognosis rise continuously after menopause. The aim of this study was to identify the differences in key miRNAs and their potential regulators through miRNA microarray analysis, functional target prediction, and clinical outcome between the elderly patients with advanced OPSC and ovarian clear cell carcinoma (OCC) who all suffered poor prognosis, to identify the pathogenetic basis, and to improve the understanding of the molecular basis of advanced OPCS in elderly patients. Through microarray analysis, we found 52 unique miRNAs with significant fold-change in expression levels, of which 9 were upregulated, whereas 43 were downregulated in OCC patients compared to elderly OPSC patients with advanced stage. Among these prediction miRNAs, miR-30a*, miR-30 $\mathrm{e}^{*}$ and $\mathrm{miR}-505^{*}$ were found to have some common cancer-related targets. Lower expression of these three miRNAs of advanced OPSC in elderly patients, all associated with significantly poorer survival rate, strongly suggesting that they could be critical oncogenes and take important roles in OPSC etiology in elderly patients with advantaged stage. Functional analyses support the above hypothesis. Their targets, ATF3, STMN1 and MYC suggest that OPSC also has aggressive biological behavior when presented with advanced stage, and support the epidemiology results that incidence and mortality of advanced OPSC increases continuously. miR-30a*, miR-30 $\mathrm{e}^{*}$ and $\mathrm{miR}-505^{*}$ may be important pathogenetic factors for OPSC in elderly patients with advanced stage. Age could be regarded as a continuous covariate in this process. This may improve the understanding of molecular underpinnings
\end{abstract}

Correspondence to: Professor Shiying Cui, Dalian Medical University, no. 9 LvShun South Road-W, Dalian 116044, P.R. China E-mail: scui2003@dlmedu.edu.cn

*Contributed equally

Key words: epithelial ovarian cancer, ovarian papillary serous carcinoma, ovarian clear cell carcinoma, microRNA of advanced OPSC in elderly patients, and provide improved diagnostic, prognostic and therapeutic approaches.

\section{Introduction}

The increasing age of the world's population has been the most dramatic demographic change since the 20th century (1). As the fifth leading cause of death in women and the first cause of gynecologic cancer death, ovarian cancer incidence and mortality rate increase continuously with advancing age and peaks in the 7th to 8th decades of life (2-6). Due to lack of symptoms in early-stage of this disease, in China, indeed the long-term survival for elderly patients with advanced disease does not exceed $20 \%$. Therefore, the poor prognosis of ovarian cancer in the elderly has been recently recognized (4). A prior report showed that, 28,082 women were diagnosed with epithelial ovarian cancer (EOC) from 1988 to 2001. The largest histology subgroup, $49.3 \%(13,835)$ of patients had ovarian papillary serous carcinoma (OPSC) (7). OPSC increases steadily after menopause, and the major patients of OPSC with advanced-stage (FIGO stages III or IV) diagnoses have a $<30 \%$ 5 -year survival rate $(7,8)$. Thus, age should be considered as an important prognostic variable. In addition, ovarian clear cell carcinoma (OCC) was frequently present at early stage (9), and has a distinct, aggressive biologic behavior with poor survival rates compared to other epithelial counterparts (7,10-12). Given that elderly advanced OPSC and OCC all carry poor prognosis, it is advantageous to study them together, find the essential differences of cancer epidemiology and biology, and then improve the understanding of the molecular basis which plays an important part in pathogenesis of elderly advanced OPCS or OCC cases.

MicroRNAs (miRNAs) are small non-coding RNA molecules of $\sim 22$ nucleotides that act post-transcriptionally to regulate gene expression (8). They show great potential in discovering new biological pathways; could be used as a diagnostic and prognostic tool for cancer patients and even serve as molecular targets for therapy.

Considering the above evidence, the OPSC patients aged $\geq 50$ years with advanced-stage and OCC patients, who all carry poor prognosis, were studied. The goal was to identify the differences of key miRNA and possible regulators through miRNA microarray chip, functional target prediction, and clinical outcome between the elderly advanced OPSC and OCC 
patients to find the pathogenic basis, and to provide insight into clinical diagnosis and therapy for advanced OPSC, especially in elderly patients.

\section{Materials and methods}

Patients and samples. Patients, who were surgically treated for ovarian cancer at the Obstetrics and Gynecology Hospital, Dalian, China between July 2004 and November 2010 were identified. The study was approved by a central and by institutional ethics committees. Corresponding 58 tumor specimens; OPSC $(n=30)$; OCC $(n=28)$ were dissected during the operations, and formalin fixed paraffin embedded (FFPE) blocks were further obtained after surgery. All pathological specimens from primary surgery were reviewed by two independent pathologists with no knowledge of patients' clinical data. Cases were classified according to the FIGO staging system. All cases were newly diagnosed, and only serous papillary ( $\geq 50$ years and FIGO stages III or IV tumors) and OCC histology were included.

MicroRNA array and data analysis. A microarray platform optimized for the analysis of a panel of 768 human miRNAs was used to analyze and compare the pattern of miRNA expression between OCC $(n=9)$ and elderly advanced OPSC $(n=8)$. Total RNA that enriched miRNAs was extracted from the FFPE tissue by using the Ambion mirVana microRNA isolation kit (Ambion, Austin, TX). The quality of total RNA was assessed using the Agilent Bioanalyzer (Agilent Technologies, Santa Clara, CA). Individual quantitative real-time polymerase chain reaction assays were formatted into a TaqMan low-density array (TLDA; Applied Biosystems), which was performed at the Shannon McCormack Advanced Molecular Diagnostics Laboratory Research Services, Dana Farber Cancer Institute, Harvard Clinic and Translational Science Center. The normalized microarray data were managed and analyzed by Statminer version 3.0 (Integromics $^{\mathrm{TM}}$ ).

MiRNA targets prediction and pathway analysis. The analysis of miRNA predicted targets was determined using several computational approaches, the MicroCosm Targets version 5 (http://www.ebi.ac.uk/enright-srv/microcosm/htdocs/targets/v5/) and miRBase (http://www.mirbase.org/). The target prediction algorithm used here is estimated to have a $20-30 \%$ false positive rate. This level of false discovery is unlikely to affect the overall network findings obviously, although the number of top predicted gene targets is large. Functional analysis of these predicted gene targets identified biologic pathways with significant involvement for gene expression. In order to retrieve only the most relevant targets, we listed only genes targeted by the miRNAs that were differentially expressed in the patient with OPSC and OCC. To further understand and interpret literature information of our unique miRNAs, an analysis of biologic pathway relationships was performed using commercially available software (Ingenuity Systems, Redwood City, CA).

Quantitative real-time $R T-P C R$. To validate key microarray results, quantitative reverse transcription was performed using the TaqMan MicroRNA Reverse Transcription Kit [Applied Biosystems (ABI), Foster City, CA] with ABI miRNA specific primers and primer kits on an Agilent Technologies Stratagent Mx3000P. Specific kits used were as follows: hsa-miR-505*: ABI\#4395198; hsa-miR-30a*: ABI\#4373062; hsa-miR-30e": ABI\#4427975. Relative expression levels were calculated using the comparative $\mathrm{Ct}\left(2^{-\Delta \Delta \mathrm{Ct}}\right)$ method with U6 small nuclear RNA as the endogenous control. Samples were analyzed in triplicate. Technical validations were carried out using a subset of the original samples that were used in the discovery phase of the study with miRNA array. Biological validation was performed using additional FFPE cases of OPSC and OCC ( $\mathrm{n}=21$ in total) (13).

qRT-PCR was performed to validate target prediction results. Total RNA $(0.5 \mu \mathrm{g})$ in $1 \mu \mathrm{l}$ of RNase-free water was used in $20 \mu \mathrm{l}$ of RT mix. Primer pairs were as follows: activating transcription factor 3 (ATF3) forward 5'-CTGCAGAAAGAGTCGGAG-3' and reverse 5'-TGAGCCCGGACAATACAC-3'; $\beta$-actin forward 5'-GACTACCTCATGAAGATC-3' and reverse 5'-GATCCACA TCTGCTGGAA-3' (Invitrogen). Real-time PCR was done using the LightCycler system and Roche fast-Start Light CyclerMaster Hybridization Probes master mix (Roche Diagnostics), and the product was detected with SYBR-Green I. Samples from at least three independent experiments, each measured in duplicate, were analyzed and the data expressed as the averages \pm SE.

Immunohistochemistry (IHC). The IHC staining procedure was described previously (14) with modification. Briefly, after dewaxing in xylene and descending concentrations of ethanol, the sections were incubated in $3 \% \mathrm{H}_{2} \mathrm{O}_{2}$ for $30 \mathrm{~min}$ to suppress endogenous peroxidase activity. The sections were further blocked with a mixed solution [10\% goat serum and 3\% albumin bovine (BSA) in PBS] for $1 \mathrm{~h}$ and incubated with the primary antibodies of ATF3 (1:100 dilution; Bioworld, cat\#BS1245); Stmn1 (1:100 dilution; Bioworld, cat\#BS3615); or MYC (1:100 dilution; Bioworld, cat\#BS2261) overnight at $4^{\circ} \mathrm{C}$. On the second day, after rinsing for $10 \mathrm{~min} \times 3$, the sections were incubated with streptavidin-peroxidase staining system kit according to the manufacturer's instructions (SP-9001, Zhongshan Golden Bridge Biotechnology Company, Beijing, China). Finally, 3,3'-diaminobenzidine (DAB) liquid chromogen substrate kit (ZLI-9032, Zhongshan Golden Bridge Biotechnology Company) offered a clean detection performance and subsequent hematoxylin staining provided a light blue counter stain contrasting with DAB. For negative controls, all the conditions were performed at the same procedures except that primary antibody was eliminated.

Statistical analysis. The results were analyzed by SPSS 15.0 (Chicago, IL). Data are expressed as arithmetic means \pm SEM of the number (n) of experiments. Samples were analyzed with repeated measures analysis of variance; differences in the incidence were analyzed using ANOVA. The differences of the positive area and integrate optical density (IOD) per vision-field of $x 400$ immunohistochemistry photographs were taken with Image-Pro plus vision 6.0. Overall survival was defined as the time from initial cytoreductive surgery to date of last follow-up or death. Survival time course was studied using the Kaplan-Meier method, and groups were compared using the log-rank test. $\mathrm{P}<0.05$ was considered statistically significant. 
Table I. Clinicopathological characteristics of the patients.

\begin{tabular}{|c|c|c|c|c|c|c|}
\hline \multirow[b]{2}{*}{ Characteristics } & \multirow{2}{*}{$\begin{array}{c}\text { Total } \\
(\mathrm{n}=58) \\
\text { No. }(\%)\end{array}$} & \multirow{2}{*}{$\begin{array}{c}\text { Advance OPSC } \\
\geq 50(\mathrm{n}=30) \\
\text { No. }(\%)\end{array}$} & \multicolumn{3}{|c|}{ OCC $(n=28)$} & \multirow[b]{2}{*}{ P-value } \\
\hline & & & $\begin{array}{c}<50(\mathrm{n}=16) \\
\text { No. }(\%)\end{array}$ & $\begin{array}{c}\geq 50(\mathrm{n}=12) \\
\text { No. }(\%)\end{array}$ & $\begin{array}{c}\text { Total OCC }(n=28) \\
\text { No. }(\%)\end{array}$ & \\
\hline \multicolumn{7}{|l|}{ Age at diagnosis } \\
\hline Median & 54.1 & 59.9 & 38.6 & 54.7 & 45.5 & 0.035 \\
\hline Range & $(29-74)$ & $(50-74)$ & $(29-48)$ & $(50-62)$ & $(29-62)$ & \\
\hline FIGO stage at diagnosis & & & & & & $<0.001^{\mathrm{c}}$ \\
\hline I & $23(39.7)$ & $0 \quad(0.0)$ & $12(75.0)$ & $11(91.7)$ & $23(82.1)$ & \\
\hline IA & $13(22.4)$ & $0 \quad(0.0)$ & $6(37.5)$ & $7(58.3)$ & $13(46.4)$ & \\
\hline $\mathrm{IC}$ & $10(17.2)$ & $0 \quad(0.0)$ & $6(37.5)$ & $4(33.3)$ & $10(35.7)$ & \\
\hline II & $2(3.4)$ & $0 \quad(0.0)$ & $2(12.5)$ & $0 \quad(0.0)$ & $2(7.1)$ & \\
\hline IIC & $2(3.4)$ & $0 \quad(0.0)$ & $2(12.5)$ & $0 \quad(0.0)$ & $2(7.1)$ & \\
\hline III $^{\mathrm{b}}$ & $31(53.4)$ & $28(93.3)$ & $2(12.5)$ & $1(8.3)$ & $3(10.7)$ & \\
\hline IIIB & $3(5.2)$ & $1 \quad(3.3)$ & $1 \quad(6.3)$ & $1(8.3)$ & $2(7.1)$ & \\
\hline IIIC & $27(46.6)$ & $26(86.7)$ & $1 \quad(6.3)$ & $0 \quad(0.0)$ & 1 (3.6) & \\
\hline IV & $2(3.4)$ & $2(6.7)$ & $0 \quad(0.0)$ & $0 \quad(0.0)$ & $\begin{array}{ll}0 & (0.0)\end{array}$ & \\
\hline \multicolumn{7}{|l|}{ Grade $^{\mathrm{d}}$} \\
\hline 1 & $2(3.4)$ & $1 \quad(3.3)$ & $0 \quad(0.0)$ & $1(8.3)$ & 1 (3.6) & \\
\hline 2 & $9(15.5)$ & $6(20.0)$ & $1 \quad(6.3)$ & $2(16.7)$ & $3(10.7)$ & \\
\hline 3 & $29(50.0)$ & $22(73.3)$ & $4 \quad(25)$ & $3(25.0)$ & $7(25.0)$ & \\
\hline Unknown & $18(31.0)$ & $1 \quad(3.3)$ & $11(68.8)$ & $6(50.0)$ & $17(63.0)$ & \\
\hline \multicolumn{7}{|l|}{ Lymphadenectomy } \\
\hline Yes & $44(75.9)$ & $20(66.7)$ & $15(93.8)$ & $9 \quad(75)$ & $24(85.7)$ & \\
\hline No & $12(20.7)$ & $9(30.0)$ & $1 \quad(6.2)$ & $2(16.7)$ & $3(10.7)$ & \\
\hline Unknown & $2(3.5)$ & $1 \quad(3.3)$ & $0 \quad(0.0)$ & $1(8.3)$ & 1 (3.6) & \\
\hline Median no. nodes resected & 20 & 19 & 18 & 23 & 20 & \\
\hline Presence of positive nodes & & & & & & 0.002 \\
\hline Yes & $14(24.1)$ & $12(40.0)$ & $1 \quad(6.3)$ & $1(8.3)$ & $2(7.1)$ & \\
\hline No & $30(51.7)$ & $8(26.7)$ & $14(87.5)$ & $8(66.7)$ & $22(78.6)$ & \\
\hline Unknown & $14(24.1)$ & $10(33.3)$ & $1 \quad(6.3)$ & $3(25.0)$ & $4(14.3)$ & \\
\hline
\end{tabular}

FIGO, International Federation of Obstetrics and Gynecology. ${ }^{a}$ Difference between groups calculated by AVON test for age and $\chi^{2}$ test for all

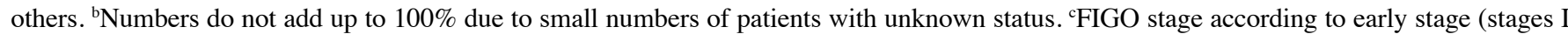
and II) and advanced stage (stages III and IV) in elder advanced OPSC and total OCC patients. ${ }^{\mathrm{d}}$ Grade according to the American Joint Committee on Cancer (AJCC) of ovarian cancer.

\section{Results}

Patient characteristics. Patient characteristics are shown in Table I. Fifty-eight patients were identified to fit the study criteria, including 30 OPSC patients (age $\geq 50$ years with advanced-stage) and 28 OCC patients. The percentage of patients with stage III disease and the presence of positive lymph nodes were all significantly higher in those patients with elderly advanced OPSC compared with those patients with elderly OCC (8.3 vs. 93.3\%).

miRNA expression pattern of OPSC and OCC. miRNAs have been reported in different types of tumors derived from different organs, including ovarian cancer. However, the pathobiological significances of aberrant miRNA expression in human ovarian cancer have not been well documented. To further characterize the unique miRNAs in EOC development, we initially analyzed miRNA expression in tumors of 8 elderly OPSC patients with advanced stage and 9 OCC patients for microarray analysis. According to the background-subtracted and normalized fluorescent intensities of array sample results, 52 unique miRNAs were detected with significant $(\mathrm{p}<0.00001$ for all), fold-change (FC) in expression level, of which 9 were upregulated, whereas 43 miRNAs were downregulated in OCC patients compared to elderly OPSC patients with advanced stage (Table II and Fig. 1A). Moreover, among the top significant unique miRNAs (FC >4), 9 were preferentially expressed in the OCC patients, whereas only 1 miRNA was most highly expressed in the elderly OPSC with advanced stage (Table II). The prediction targets of these 9 miRNAs are shown in Fig. 1B and C. 
Table II. The miRNA expression in elderly OPSC and OCC patients with advanced stage.

\begin{tabular}{|c|c|c|c|c|c|c|}
\hline miR name & P-value & $\begin{array}{l}\text { FDR } \\
(\%)^{\mathrm{a}}\end{array}$ & $\begin{array}{l}\text { Fold-change } \\
\text { (FC) }\end{array}$ & $\begin{array}{l}\text { Fold-change } \\
\text { grade }\end{array}$ & $\begin{array}{l}\text { Higher expression } \\
\text { associated with }\end{array}$ & Cancer involvement $\mathrm{t}^{\mathrm{b}}$ \\
\hline hsa-miR-130a* & $1.40 \mathrm{E}-08$ & $<0.01$ & 0.003552833 & IV & OPSC & Brain, liver \\
\hline hsa-miR-188-3p & 8.87E-06 & $<0.01$ & 0.62304526 & $\mathrm{I}$ & OPSC & \\
\hline hsa-miR-29b- $2^{*}$ & $3.33 \mathrm{E}-07$ & $<0.01$ & 10.83658116 & III & $\mathrm{OCC}$ & Thyroid, uterus, AML \\
\hline hsa-miR-208a & 8.87E-06 & $<0.01$ & 0.62304526 & I & OPSC & \\
\hline hsa-miR-208b & 8.87E-06 & $<0.01$ & 0.62304526 & I & OPSC & \\
\hline hsa-miR-219-2-3p & 8.87E-06 & $<0.01$ & 0.62304526 & I & OPSC & \\
\hline hsa-miR-220b & 8.87E-06 & $<0.01$ & 0.62304526 & I & OPSC & \\
\hline hsa-miR-220c & 8.87E-06 & $<0.01$ & 0.62304526 & I & OPSC & \\
\hline hsa-miR-30a & $1.47 \mathrm{E}-06$ & $<0.01$ & 4.376533535 & I & OPSC & $\begin{array}{l}\text { Lung, colon, myeloid } \\
\text { leukemia, renal }\end{array}$ \\
\hline hsa-miR-30a* & $1.30 \mathrm{E}-08$ & $<0.01$ & 11.97926536 & II & $\mathrm{OCC}$ & $\begin{array}{l}\text { Colon, breast, } \\
\text { esophagus, bladder }\end{array}$ \\
\hline hsa-miR-30c-2* & $2.72 \mathrm{E}-07$ & $<0.01$ & 226.4780393 & IV & $\mathrm{OCC}$ & $\begin{array}{l}\text { Endometrial, stomach, } \\
\text { ovarian, breast, colon }\end{array}$ \\
\hline hsa-miR-30e & $5.97 \mathrm{E}-09$ & $<0.01$ & 8.945290166 & II & $\mathrm{OCC}$ & $\begin{array}{l}\text { Ovarian, brain, } \\
\text { epithelium, esophagus, } \\
\text { breast, lung, colon }\end{array}$ \\
\hline hsa-miR-302a & $8.87 \mathrm{E}-06$ & $<0.01$ & 0.62304526 & I & OPSC & Skin, germ cell \\
\hline hsa-miR-302c & 8.87E-06 & $<0.01$ & 0.62304526 & I & OPSC & Breast \\
\hline hsa-miR-325 & 8.87E-06 & $<0.01$ & 0.62304526 & I & OPSC & \\
\hline hsa-miR-326 & 8.87E-06 & $<0.01$ & 0.62304526 & $\mathrm{I}$ & OPSC & Brain \\
\hline hsa-miR-346 & 8.87E-06 & $<0.01$ & 0.62304526 & I & OPSC & Follicular thyroid \\
\hline hsa-miR-367 & 8.87E-06 & $<0.01$ & 0.62304526 & I & OPSC & Ependymomas \\
\hline hsa-miR-376b & 8.87E-06 & $<0.01$ & 0.62304526 & I & OPSC & \\
\hline hsa-miR-377 & $8.87 \mathrm{E}-06$ & $<0.01$ & 0.62304526 & I & OPSC & Breast \\
\hline hsa-miR-380 & 8.87E-06 & $<0.01$ & 0.62304526 & I & OPSC & \\
\hline hsa-miR-384 & 8.87E-06 & $<0.01$ & 0.62304526 & I & OPSC & Laryngeal, breast \\
\hline hsa-miR-448 & 8.87E-06 & $<0.01$ & 0.62304526 & I & OPSC & Prostate, breast \\
\hline hsa-miR-485-5p & 8.87E-06 & $<0.01$ & 0.62304526 & I & OPSC & Ovarian \\
\hline hsa-miR-490-3p & 8.87E-06 & $<0.01$ & 0.62304526 & I & OPSC & Colon \\
\hline hsa-miR-496 & 8.87E-06 & $<0.01$ & 0.62304526 & I & OPSC & Ovary, AML \\
\hline hsa-miR-505* & $4.98 \mathrm{E}-06$ & $<0.01$ & 6.122042066 & II & OCC & Bladder \\
\hline hsa-miR-516b & 8.87E-06 & $<0.01$ & 0.62304526 & I & OPSC & \\
\hline hsa-miR-518a & 8.87E-06 & $<0.01$ & 0.62304526 & I & OPSC & Follicular lymphoma \\
\hline hsa-miR-518c & 8.87E-06 & $<0.01$ & 0.62304526 & I & OPSC & Colon, bladder \\
\hline hsa-miR-518d-5p & 8.87E-06 & $<0.01$ & 0.62304526 & I & OPSC & \\
\hline hsa-miR-519c-3p & 8.87E-06 & $<0.01$ & 0.62304526 & I & OPSC & Lung \\
\hline hsa-miR-520e & 8.87E-06 & $<0.01$ & 0.62304526 & I & OPSC & Cholangio, liver \\
\hline hsa-miR-524-5p & 8.87E-06 & $<0.01$ & 0.62304526 & I & OPSC & \\
\hline hsa-miR-525-5p & 8.87E-06 & $<0.01$ & 0.62304526 & I & OPSC & \\
\hline hsa-miR-544 & 8.87E-06 & $<0.01$ & 0.62304526 & I & OPSC & \\
\hline hsa-miR-548a-5p & 8.87E-06 & $<0.01$ & 0.62304526 & I & OPSC & \\
\hline hsa-miR-548b-3p & 8.87E-06 & $<0.01$ & 0.62304526 & I & OPSC & \\
\hline hsa-miR-556-3p & $8.87 \mathrm{E}-06$ & $<0.01$ & 0.62304526 & I & OPSC & Prostate \\
\hline hsa-miR-556-5p & 8.87E-06 & $<0.01$ & 0.62304526 & I & OPSC & Prostate \\
\hline hsa-miR-576-5p & 8.87E-06 & $<0.01$ & 0.62304526 & I & OPSC & Ovary \\
\hline hsa-miR-615-3p & 8.87E-06 & $<0.01$ & 0.62304526 & I & OPSC & $\begin{array}{l}\text { Breast, colon, prostate, } \\
\text { blood, ovary }\end{array}$ \\
\hline
\end{tabular}


Table II. Continued.

\begin{tabular}{|c|c|c|c|c|c|c|}
\hline miR name & P-value & $\begin{array}{l}\text { FDR } \\
(\%)^{\mathrm{a}}\end{array}$ & $\begin{array}{l}\text { Fold-change } \\
\qquad \text { (FC) }\end{array}$ & $\begin{array}{l}\text { Fold-change } \\
\text { grade }\end{array}$ & $\begin{array}{l}\text { Higher expression } \\
\text { associated with }\end{array}$ & Cancer involvement ${ }^{\mathrm{b}}$ \\
\hline hsa-miR-615-5p & 8.87E-06 & $<0.01$ & 0.62304526 & $\mathrm{I}$ & OPSC & $\begin{array}{l}\text { Breast, colon, prostate, } \\
\text { blood, ovary }\end{array}$ \\
\hline hsa-miR-628-3p & $2.43 \mathrm{E}-07$ & $<0.01$ & 6.140440621 & II & OCC & Brain, breast, thyroid \\
\hline hsa-miR-624 & $8.87 \mathrm{E}-06$ & $<0.01$ & 0.62304526 & I & OPSC & \\
\hline hsa-miR-875-3p & $8.87 \mathrm{E}-06$ & $<0.01$ & 0.62304526 & I & OPSC & Pancreas \\
\hline hsa-miR-885-3p & 8.87E-06 & $<0.01$ & 0.62304526 & I & OPSC & Lung, brain \\
\hline hsa-miR-885-5p & $5.11 \mathrm{E}-06$ & $<0.01$ & 8.409273981 & II & OCC & Renal, brain, ovary \\
\hline hsa-miR-890 & 8.87E-06 & $<0.01$ & 0.62304526 & I & OPSC & Nasopharyngeal \\
\hline hsa-miR-891b & 8.87E-06 & $<0.01$ & 0.62304526 & I & OPSC & \\
\hline hsa-miR-892a & 8.87E-06 & $<0.01$ & 0.62304526 & I & OPSC & \\
\hline hsa-let-7e* & $5.99 \mathrm{E}-06$ & $<0.01$ & 4.703680442 & I & OPSC & $\begin{array}{l}\text { Head and neck, } \\
\text { retinoblastoma, pleural }\end{array}$ \\
\hline
\end{tabular}

OCC patients vs. stage III, IV of elderly OPSC with advanced stage, $\mathrm{p}<0.00001$ for all. FDR, false discovery rate; FC, fold-change; AML, acute myeloid leukemia; FC grade I, $1<\mathrm{FC} \leq 5$; grade II, $5<\mathrm{FC} \leq 10$; grade III, $10<\mathrm{FC} \leq 15$; grade IV, $\mathrm{FC}>200$. ${ }^{a} 1 \%$ FDR predicts that this list is $99 \%$ accurate. ${ }^{b}$ Information obtained from PubMed (http://www.ncbi.nlm.nih.gov/pubmed/), Elsevier ScienceDirect (http://www.sciencedirect.com/) and previous reports.

Unique miRNAs and their co-target prediction. The Micro Cosm Targets version 5 and miRBase were used to analyze predicted targets for the 10 top significantly unique miRNAs highly expressed in OPSC vs. OCC with p-values $<0.00001$, and $\mathrm{FC}>4$-fold. The target prediction algorithm used here is estimated to have a $20-30 \%$ false positive rate. This level of false discovery is unlikely to affect the overall network findings obviously, although the number of top predicted gene targets is large. Functional analysis of these predicted gene targets identified biologic pathways with significant involvement for gene expression. In order to retrieve only the most relevant targets, we listed only genes targeted by miR-30a*, miR-30 $e^{*}$ and miR-505* that were found having some targets in common suggesting they might play important roles in pathogenesis between OCC and elderly advanced OPSC together or partly (Figs. 1D and 2). Fig. 3 show the function analysis of miR-30a*, miR-30 $\mathrm{e}^{*}$ and miR-505*.

$q R T-P C R$ validation for microarray results. In order to confirm microarray results, RNA was isolated from a new set of FFPE tissues as described above to increase the likelihood that the observed differences in miRNA expression profiles represent biologically significant changes. MiR-30a*, miR-30e* and $\mathrm{miR}-505^{*}$ were the upregulated miRNAs in OCC with different fold-changes (from 6-12) when compared with OPSC by using microarray analysis. Validation of miRNA expression analysis was repeated with qRT-PCR (miR-30a*, miR-30 ${ }^{*}$ and $\mathrm{miR}-505^{*}$ ) and representative analyses are shown in Fig. 4A (unsupervised hierarchical clustering of validation) and Fig. 4B. Through this additional analysis, the expression patterns found in the arrays could be confirmed. In keeping with microarray results, miR-30a*, miR-30 ${ }^{*}$ and miR-505* were all highly expressed in OCC with statistical significance.
Validations of miRNA target prediction and their top co-targets. In target prediction experiment using multiple software, ATF3 was predicted as a potential co-target of miR-30a*, miR-30 $\mathrm{e}^{*}$ and $\mathrm{miR}-505^{*}$, and presented as a regulator in the different pathways, which include cancer and cell death. At the same time, we found that MYC is the co-target of miR-30a* and miR-30e*; stathmin1 (STMN1) is co-target of miR-30a* and miR-505*; HLA-DPB1 is co-target of miR-30 $e^{*}$ and miR-505*. To examine the biological significance of these miRNAs in ovarian cancer, we focus on the ATF3, STMN1 and MYC, which were already proven to be cancer markers.

Immunohistochemical assay for the ATF3, STMN1 and MYC proteins showed a relevant upregulation in OPSC cells compared to OCC cells (Fig. 5A). It is clear that these co-targets were all extensively distributed in the cytoplasm of cancer cells in the tissue of OPSC samples (Fig. 5A1-3) comparing with the OCC sections (Fig. 5A4-6). Through analysis with Image-Pro plus vision 6.0, positive area and IOD per vision-field of $\mathrm{x} 400$ immunohistochemistry photographs were detected. These results also support the conclusions of the immunohistochemical assay (Fig. 5B and C).

Overall survival analysis of elderly advanced OPSC and OCC patients. We next compared the prognosis of elderly advanced OPSC patients in groups stratified according the expression levels of individual miRNAs. For each miRNA, we divided the samples into two sub-sections according to high and low expression level of the miR-30a*, miR-30e* and miR-505* (Fig. 6A-C). The association of these three miRNAs with survival indicated that lower expression of miR-30a*, miR-30 ${ }^{*}$ and miR-505 ${ }^{*}$, all associated with poorer prognosis. We also studied the overall survival of ovarian cancer patients with OPSC and OCC (Fig. 6D). They were 


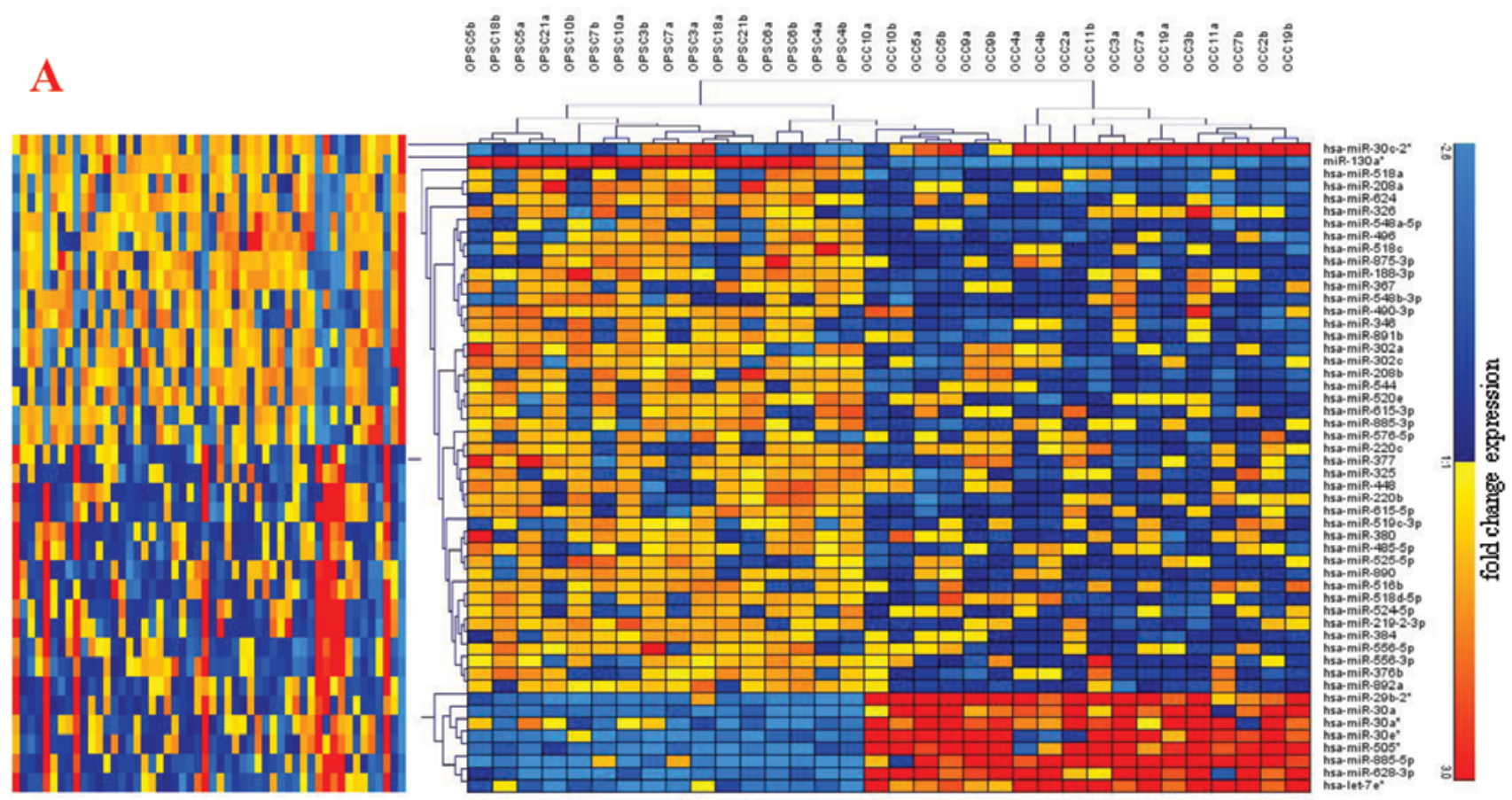

B

OCC patients (< 50 years old)

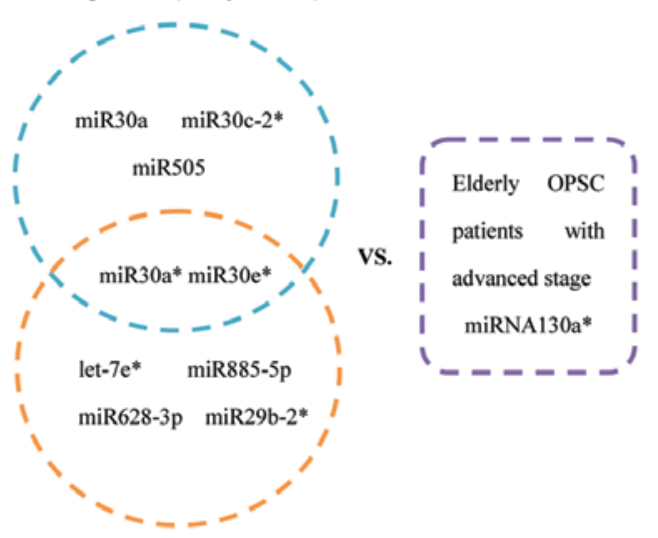

OCC patients ( $\geq 50$ years old)

C

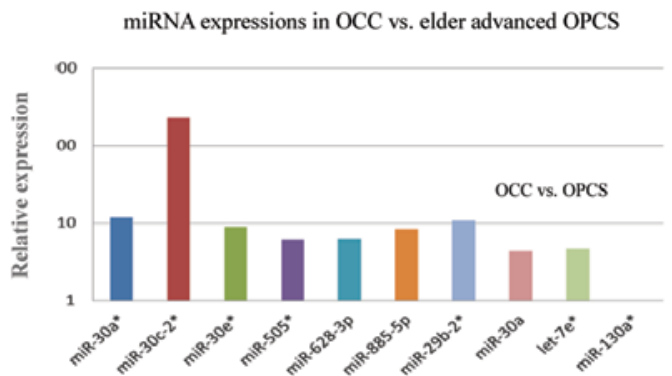

D miR-30a*

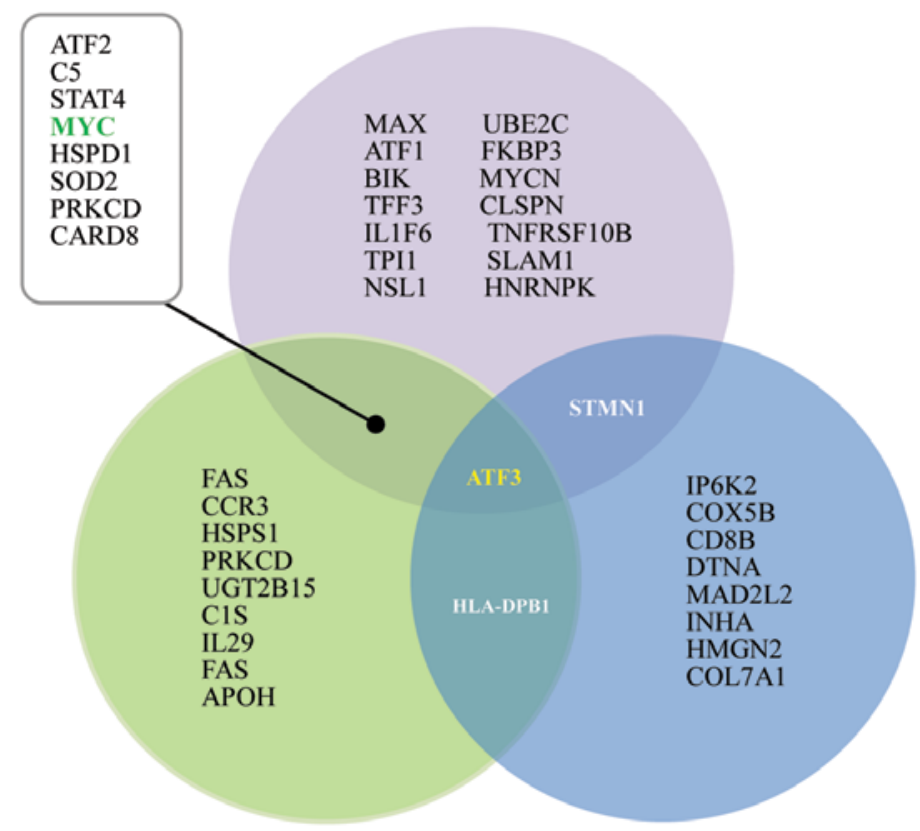

miR-30e*

Figure 1. Target predictions of miRNAs through microarray analysis. (A) Results of the unsupervised hierarchical clustering of microarray assay by qRT-PCR Among the top significantly unique miRNAs (fold-change $>4$, FDR $<0.01$, B and C) using microarray platform to predict target miRNAs, 9 miRNAs are preferentially expressed in the OCC patients when compared to the elderly OPSC with advanced stage, and their relative expressions are shown in the column map. Only miR-130a*, is highly expressed in OPSC (its FC value is 0.0035528 ). These 9 miRNAs are distributed in different ages of OCC patients, and miR-30 ${ }^{*}$ and miR-30 $\mathrm{e}^{*}$ are the co-prediction targets of younger ( $<50$ years) and elderly ( $\geq 50$ years) OCC patients. (D) Venn diagram of selected miRNAs and their putative gene targets. The MicroCosm Targets version 5 and miRBase were used to analyze predicted targets for the 10 top significantly unique miRNAs which were highly expressed in OPSC vs. OCC with $\mathrm{p}<0.00001$, and change $>4$-fold. Three miRNAs were found with some common targets, including miR-30a", miR-30e" and miR-505*. These events suggest they might have an important role in ovarian cancer differences between OCC and elder advanced OPSC together or partly, and ATF3 is the co-target of these relevant miRNAs. 
miR-30a*:

$\mathbf{A}$

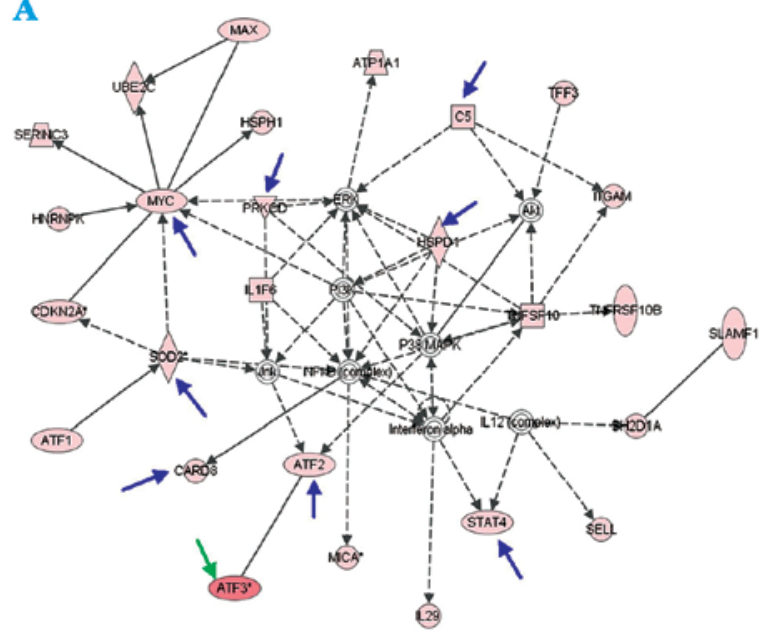

miR-30e*:

$\mathbf{C}$

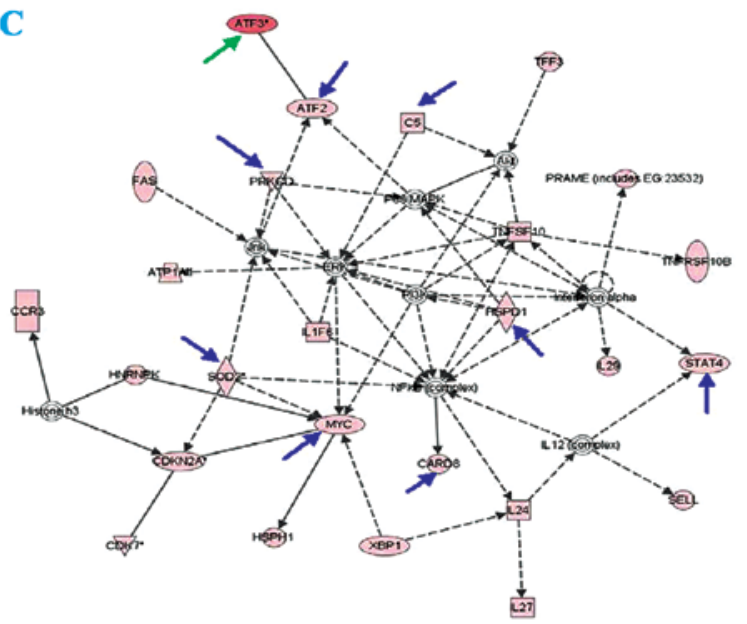

miR-505*:

$\mathbf{E}$

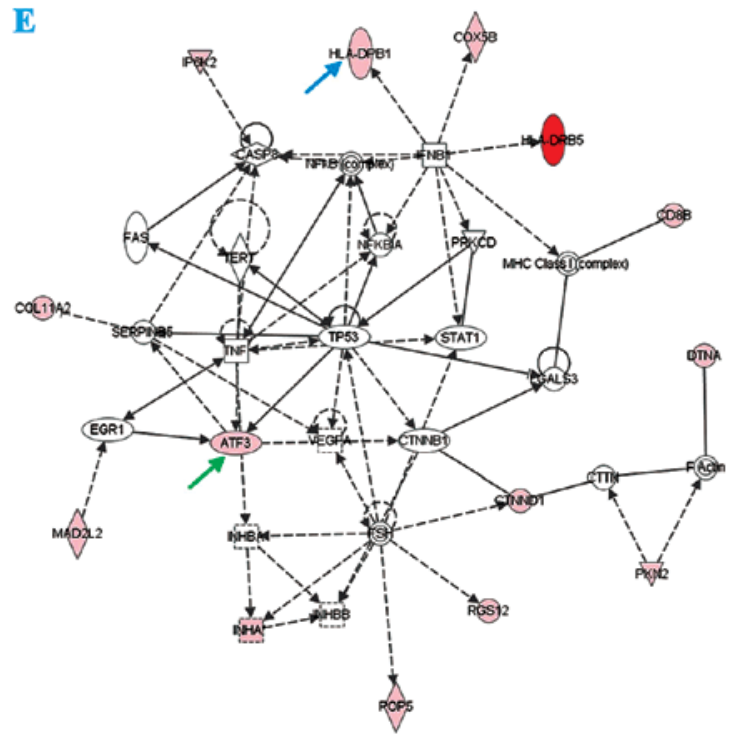

B

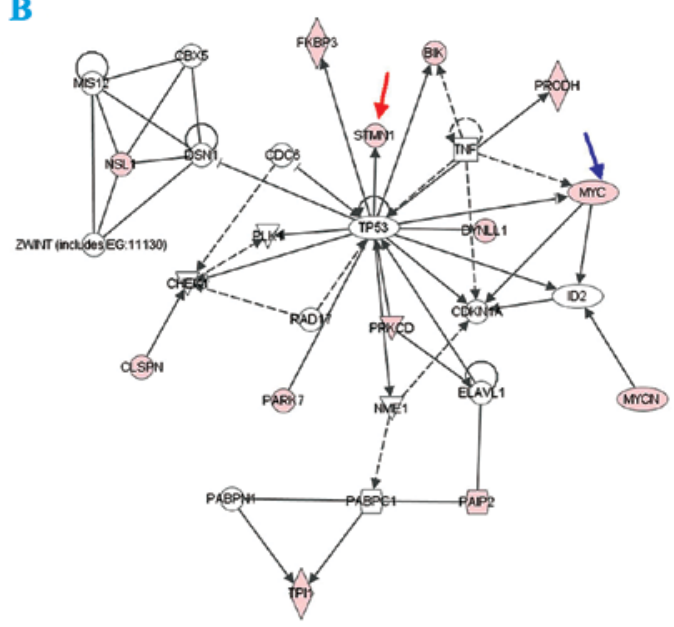

D

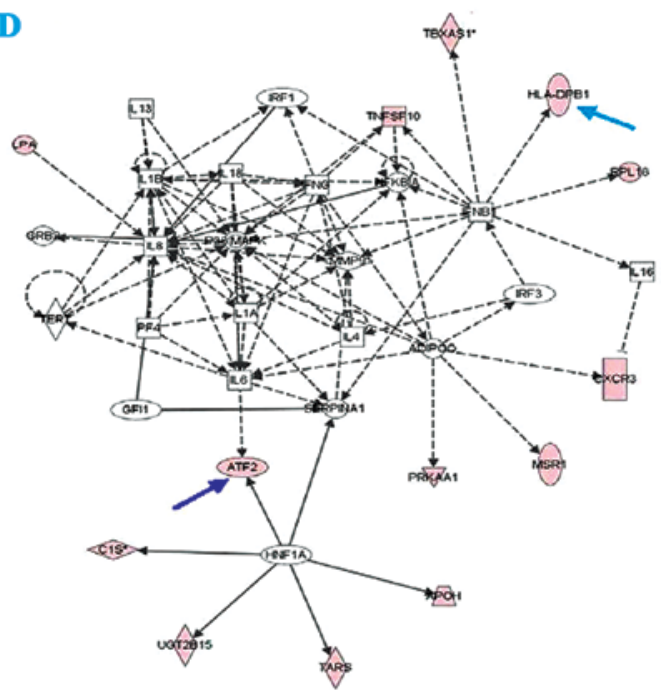

$\mathbf{F}$

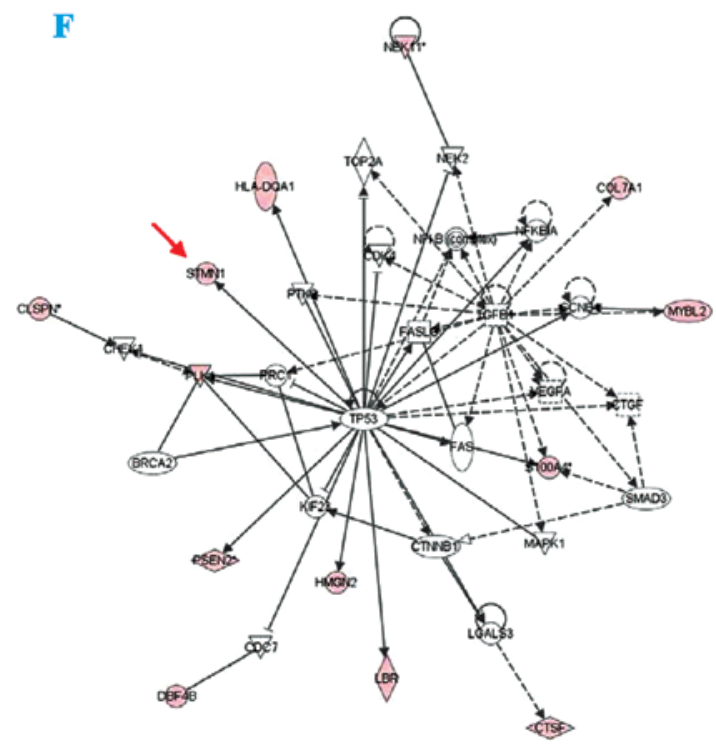

Figure 2. The analysis of prediction protein targets for miR-30a*, miR-30e and miR-505* were determined through using the MicroCosm Targets version 5 (http://www.ebi.ac.uk/enright-srv/microcosm/htdocs/targets/v5/) and miRBase (http://www.mirbase.org/). Green arrows, co-targets of miR-30a*, miR-30 ${ }^{*}$ and

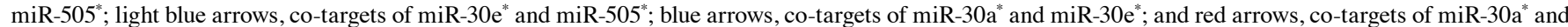
miR-505*. Associated network functions are: (A) DNA replication, recombination and repair, cancer, cell death of miR-30a*; (B) cell cycle, cancer, cell death of miR-30a*; (C) cell morphology, cancer, cell death of miR-30e*; (D) dermatological diseases and conditions, cellular movement, hematological system development and function of miR-30e*; (E) cancer, cellular growth and proliferation, cell death of miR-505*; and (F) cell cycle, cancer, renal and urological disease of miR-505*. 


miR-30a*
Cell Cycle
Inflammatory Disease
Genetic Disorder
Cellular Development
Respiratory System Development and function
Gene Expression
Cancer
Cell Death

miR-30e*

Cell Cycle

Organismal Functions

Inflammatory Disease

Cellular Development

Small Molecule Biochemistry

Cell Death

Connective Tissue Disorders

Cancer

miR-505*

Cellular Assembly and Organization

Lipid Metabolism

Small Molecule Biochemistry

Cellular Development

Cell Death

Cell-To-Cell Signaling and Interaction

Genetic Disorder

Cancer
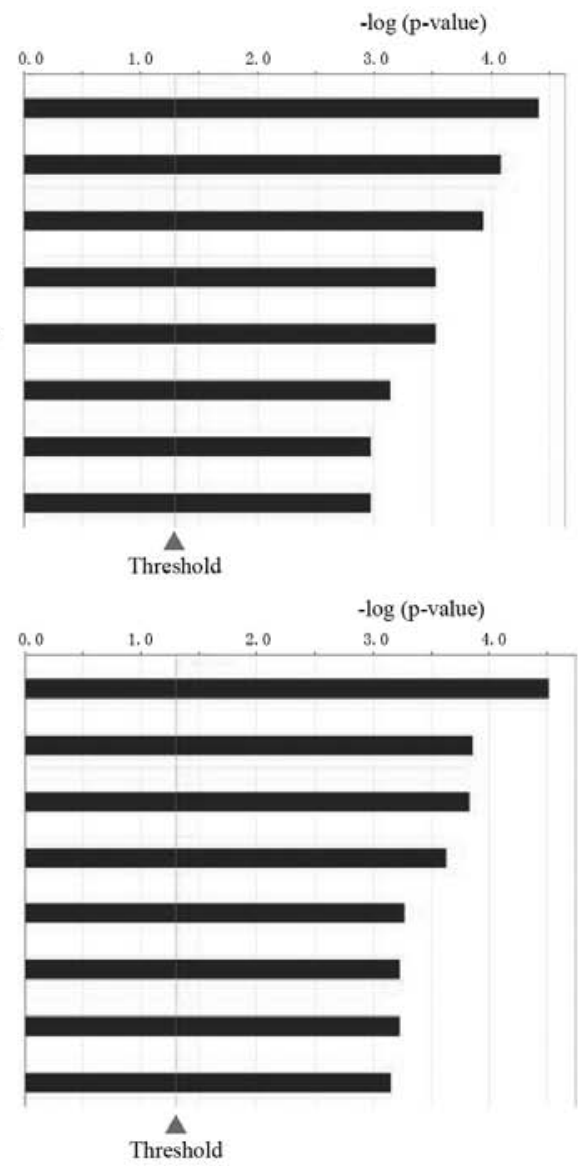

- $\log$ (p-value)

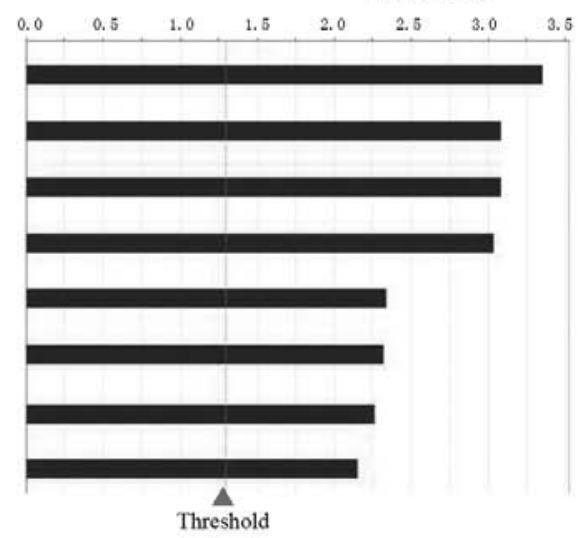

Figure 3. Analysis of miR-30a*, miR-30e and miR-505*.

associated with significant differences (OPSC was lower, $\log$-rank $\mathrm{p}<0.01)$ in overall survival.

\section{Discussion}

EOC is the most important cause of gynecologic malignancyrelated mortality in women (15) rising continuously with advancing age. Some recent reports show that cancer incidence is 11 -fold greater for the older population $(4,16)$. Therefore, it is necessary to study and understand cancer epidemiology, biology and therapy to the elderly patient. The incidence of OPSC increases steadily after menopause, and this histologic subgroup makes up the largest part of EOC patients.
Considering that for most women menopause is after the age of 50 years, OPSC patients aged $\geq 50$ years with advanced-stage as well as OCC patients were studied. The purpose was to apply microarray analysis to investigate the difference, especially molecular mechanism between elderly OPSC with advanced stage and OCC, which both carry poor prognosis $(8,9)$. Through miRNA microarray and target prediction analysis, 10 miRNAs were found to be differentially expressed in tumor from OPSC vs. OCC ( $p<0.00001$ and FC $>4)$. Moreover, in order to retrieve only the most relevant targets, we only investiged three miRNAs (miR-30a*, miR-30e* and miR-505*) which were found with some common cancer associated pathways. We confirmed these predictions and relations. Biological pathways were predicted 

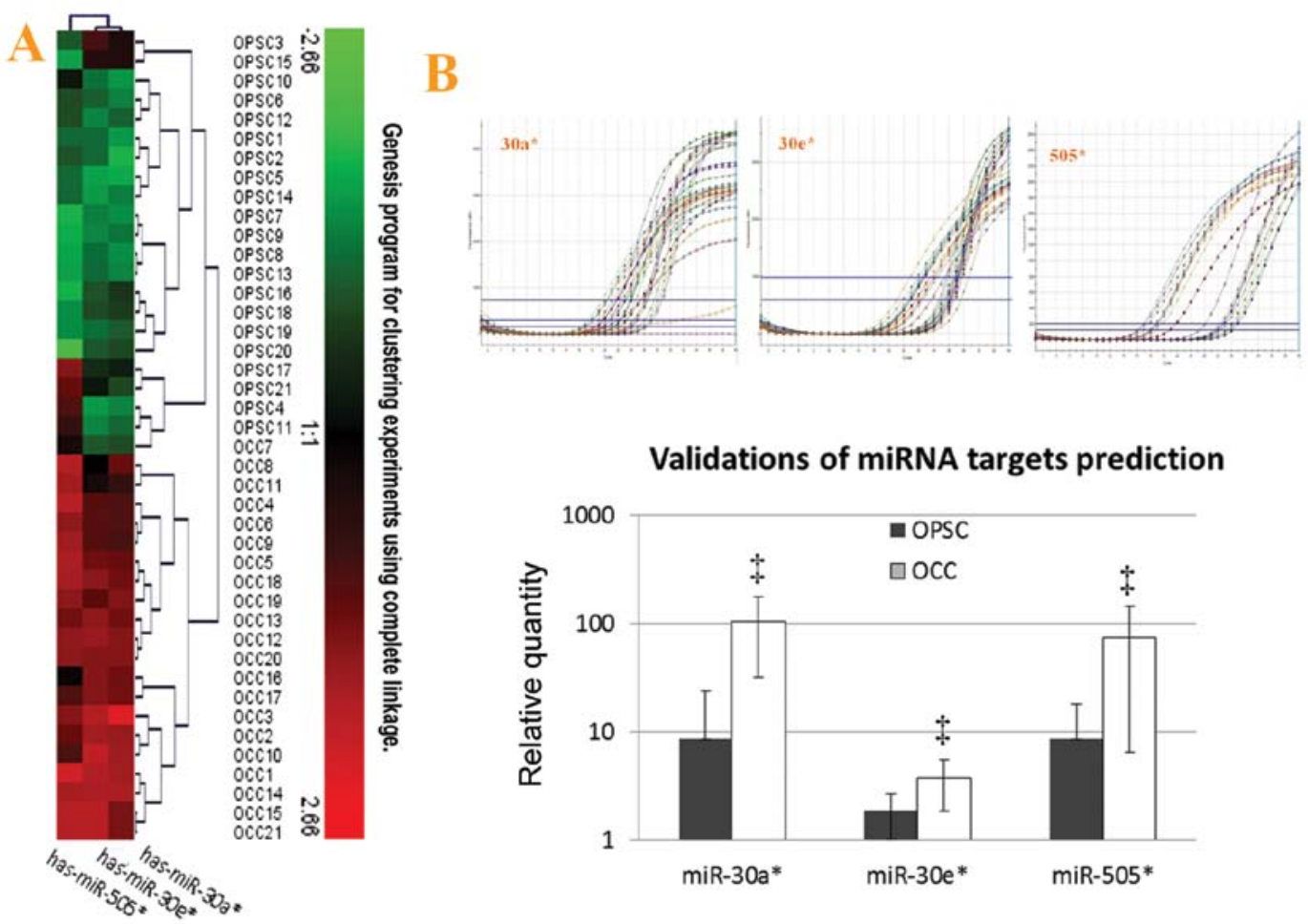

Figure 4. MicroRNA validation with real-time PCR for microarray analysis. (A) Unsupervised clustering of validation set samples, according to miR-30a*,

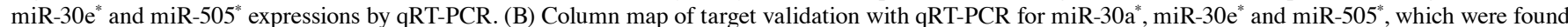
with some common targets. In keeping with microarray results, miR-30a*, miR-30 $\mathrm{e}^{*}$ and miR-505* were highly expressed in OCC with significance. Compared with the OCC, ${ }^{\star} \mathrm{p}<0.01$
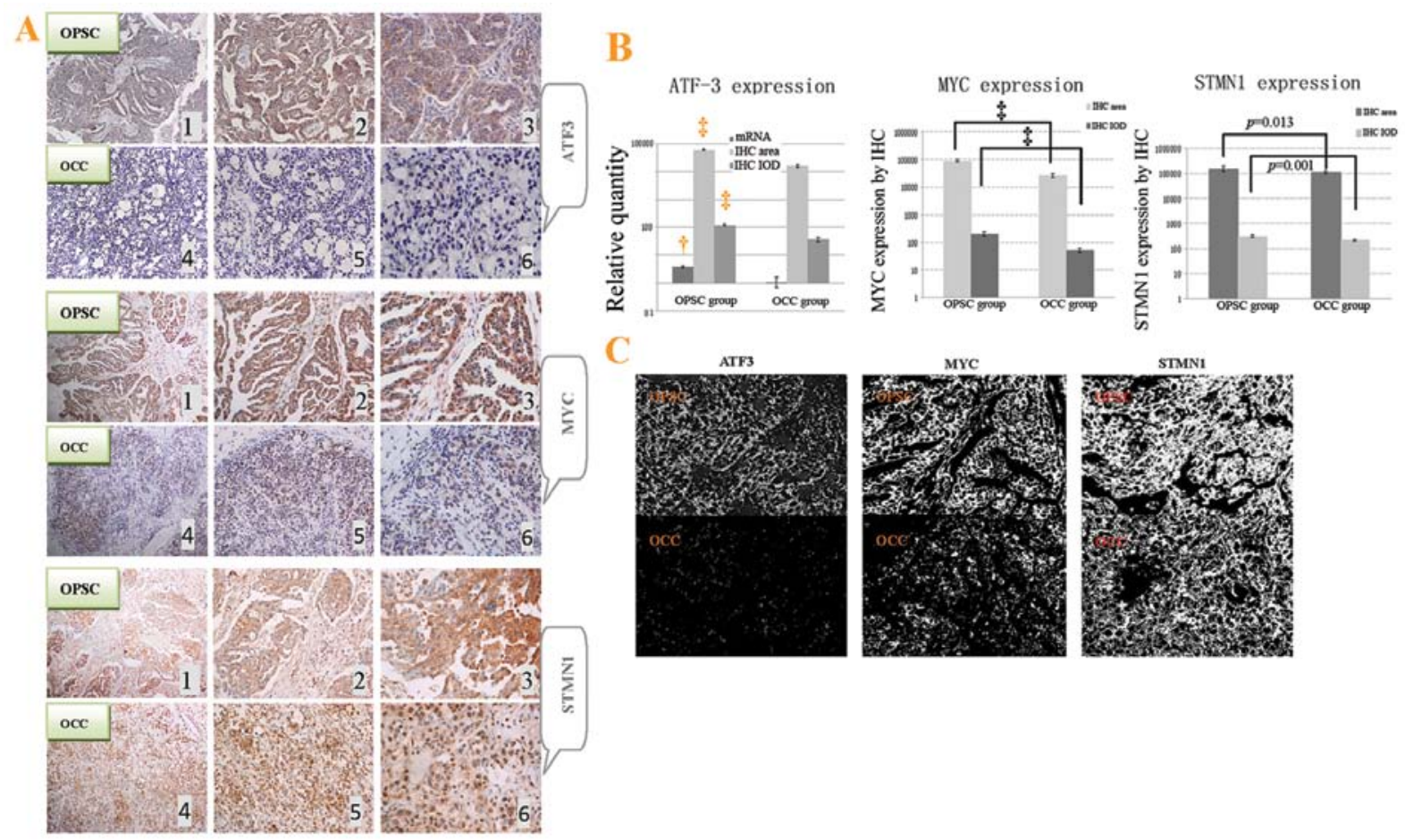

Figure 5. ATF3, STMN1 and MYC protein expressions in paraffin-embedded tissues in the immunohistochemical assay, and overall survival of ovarian cancer patients with elderly advanced OPSC and OCC. (A) Different expression of ATF3, STMN1 and MYC protein between OPSC and OCC cells by immunohistochemistry (IHC) with hematoxylin counter staining. ATF3, STMN1 and MYC, are extensively expressed in the cytoplasm of OPSC tumor cells (A1, 2 and 3) and poorly expressed in OCC tissues (A4, 5 and 6). Magnifications from left to right are x100, x200 and x400, respectively. (B) As the only co-target of these miRNAs, ATF3 mRNA expression was also detected through real-time PCR. Different expressions for positive area and integrate optical density (IOD) of ATF3, STMN1 and MYC (per vision-field of $x 400$ photograph taken with Image-Pro plus vision 6.0) between OPSC and OCC tumor through immunohistochemistry staining, respectively, are shown. (C) Image (x400) showing positive staining area of above proteins by Image-Pro plus vision 6.0, respectively. Compared with the OCC, ${ }^{\dagger} \mathrm{p}<0.05$, and ${ }^{\ddagger} \mathrm{p}<0.01$. 

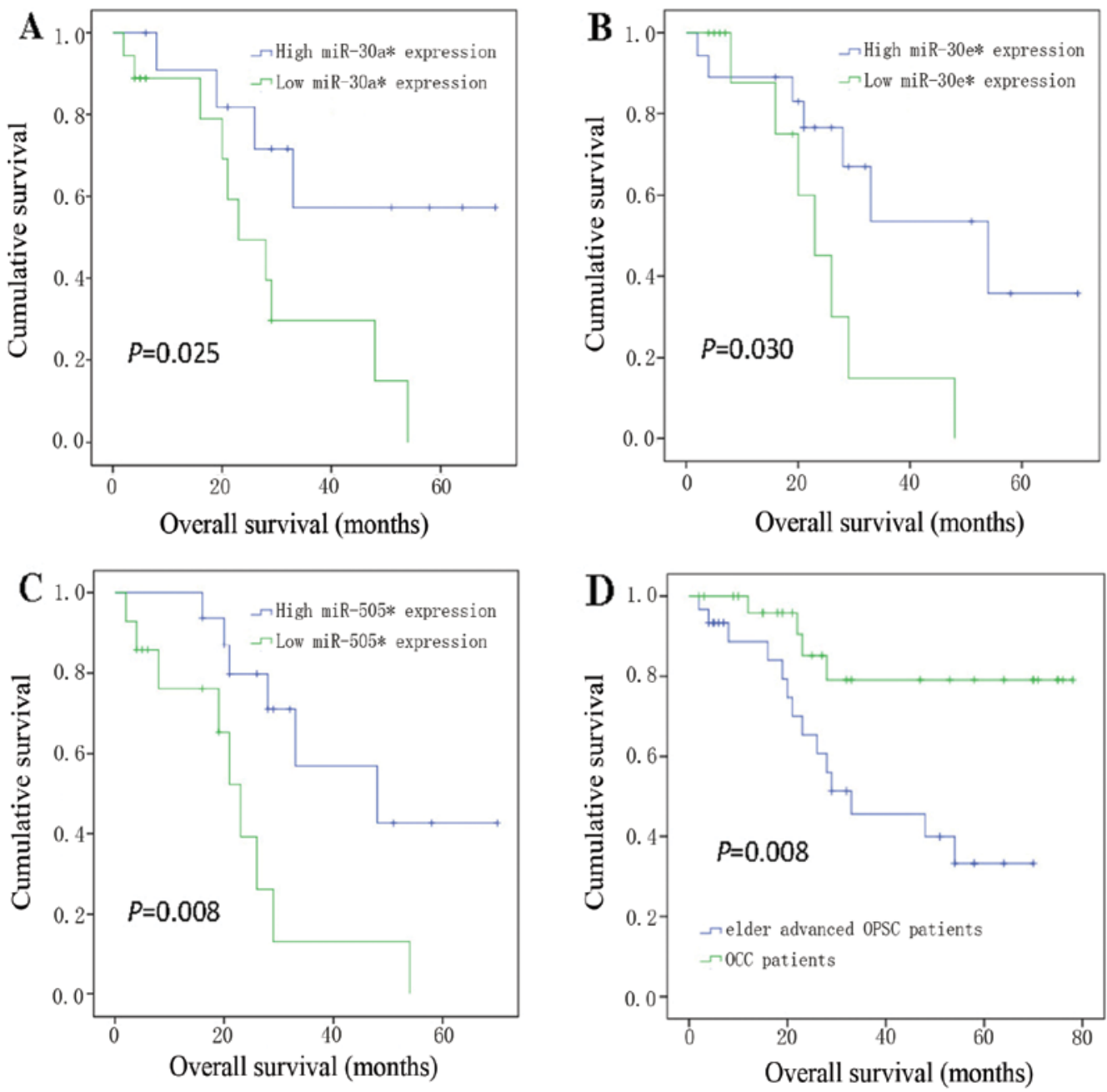

Figure 6. Kaplan-Meier curves showing overall survival for groups of elderly OPSC patients with advanced disease (A, B and C), stratified by expression levels of (A) hsa-miR-30a*, (B) hsa-miR-30e" and (C) hsa-miR-505*; (D) overall survival of ovarian cancer patients with OPSC and OCC. The samples of elder advanced OPSC patient were divided into two groups with high expression levels (blue line) and low expression levels (green line) of (A) hsa-miR-30a* ( $\mathrm{p}=0.0025$ ),

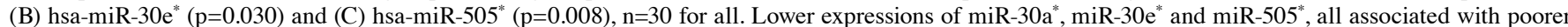
prognosis. (D) Overall survival associated with the histological type, elder advanced OPSC and OCC, was also tested ( $\mathrm{n}=58$, $\mathrm{p}=0.008$ ). The overall survival of elder advanced OPSC is obviously lower than OCC patients. P-values are calculated by log-rank test comparing the low and high expression groups. Censoring events are marked by vertical lines.

using multiple software, and ATF3 was indicated as an only potential co-target of these three miRNAs.

Advanced OPSC has its own specific pathogenic factors, especially in elderly patients. Lower expressions of miR-30a*, miR-30 ${ }^{*}$ and miR-505* were validated in elderly advanced OPSC patients consistent with microarray analysis. The survival analysis was investigated for elderly advanced OPSC patients in groups stratified according the expression levels of individual miRNAs, and the results revealed that lower expressions of miR-30a ${ }^{*}$, miR-30 ${ }^{*}$ and miR-505, all associated with significantly poorer prognosis. The results strongly suggested that they could be critical oncogenes and take important roles in ovarian cancer etiology with advantaged stage.

In order to validate our above hypothesis, we selected some typical downstream prediction targets which have associated with cancer as supporting evidence. ATF3 is a member of the ATF/cyclic adenosine monophosphate response element binding family of transcription factors $(17,18)$. It is expressed at low levels in normal and quiescent cells, but can rapidly and significantly increase in various cancers (19). Previous research supports that overexpression of ATF3 could play an oncogenic role in carcinogenesis. These studies provide correlative evidence that ATF3 expression contributes to the successful propagation of human cancer (17,20-22), and also could promote metastasis, cell adhesion and invasion in vitro and in vivo $(23,24)$. Furthermore, STMN1 overexpression is associated with polyploidy, tumor-cell invasion, early recurrence and poor prognosis in human hepatoma and ovarian cancer (25-27). MYC was also proven to have a pivotal role as a regulator of tumorigenesis in numerous human cancers of diverse origin (28). In our results, they all increased more in elderly advanced OPSC group, strongly supporting our pathogenic hypothesis for miR-30a* miR-30 $\mathrm{e}^{*}$ and miR-505*, and suggesting that OPSC also has aggressive biologic behavior when presented with advanced-stage. Epidemiology results show that incidence and mortality rate of advanced OPSC rise continuously with advancing age. Previous reports have shown that women with OCC have a poorer prognosis compared to 
serous ovarian cancer $(7,29)$. However, most of these studies originate from limited research with different age and stage thus yielding different prognosis. In the current study, we found the survival rate of elderly advanced OPSC was significantly shorter than that for patients with OCC. Although, there are no data supporting the concept that elderly women with cancer should receive differential treatment based on age alone, the actual condition is that cancer risk increases with age (4). Pignata and Vermorken (1) already demonstrated that ageing is associated with important changes which can affect pharmacologic properties of cytotoxic agents including pharmacokinetic, pharmacodynamic and toxicity profiles. Therefore, age should be regarded as an important prognostic variable in the pathogenesis and treatment of advanced OPSC. Major questions about ovarian cancer in older-aged women need urgent attention from the research community since the incidence and the prognosis of this population is continuously worsening (1).

The above data of this research supported our hypothesis and strongly suggest that miR-30a*, miR-30 ${ }^{*}$ and miR-505* may be the important pathogenic factors for elderly OPSC patients with advanced stage. This is the first report indicating and validating the differences and significance of miR-30a*, miR-30a* and miR-505*, and their targets (ATF3, STMN1 and MYC) in elderly OPSC with advanced stage. We hope this can improve understanding of molecular underpinnings during EOC development and progression, especially in elderly advanced OPSC patients; and to identify putative targets, including mRNA and proteins, which may open a new field for the understanding of this disease and providing improved diagnostic, prognostic and therapeutic approaches to individual patients, especially to the elderly.

\section{Acknowledgements}

This study was supported through the Chinese Ministry of science and technology projects (no. 2008DFA30720).

\section{References}

1. Pignata S and Vermorken JB: Ovarian cancer in the elderly. Crit Rev Oncol Hematol 49: 77-86, 2004.

2. Boren T, Xiong Y, Hakam A, et al: MicroRNAs and their target messenger RNAs associated with ovarian cancer response to chemotherapy. Gynecol Oncol 113: 249-255, 2009.

3. Liu JF, Hirsch MS, Lee H and Matulonis UA: Prognosis and hormone receptor status in older and younger patients with advanced-stage papillary serous ovarian carcinoma. Gynecol Oncol 115: 401-406, 2009.

4. Moore DH, Kauderer JT, Bell J, Curtin JP and Van Le L: An assessment of age and other factors influencing protocol versus alternative treatments for patients with epithelial ovarian cancer referred to member institutions: a Gynecologic Oncology Group study. Gynecol Oncol 94: 368-374, 2004.

5. Shih KK, Qin LX, Tanner EJ, et al: A microRNA survival signature (MiSS) for advanced ovarian cancer. Gynecol Oncol 121: 444-450, 2011

6. Yancik R, Ries LG and Yates JW: Ovarian cancer in the elderly: an analysis of Surveillance, Epidemiology, and End Results Program data. Am J Obstet Gynecol 154: 639-647, 1986.

7. Chan JK, Teoh D, Hu JM, Shin JY, Osann K and Kapp DS: Do clear cell ovarian carcinomas have poorer prognosis compared to other epithelial cell types? A study of 1411 clear cell ovarian cancers. Gynecol Oncol 109: 370-376, 2008.
8. Wyman SK, Parkin RK, Mitchell PS, et al: Repertoire of microRNAs in epithelial ovarian cancer as determined by next generation sequencing of small RNA cDNA libraries. PLoS One 4: e5311, 2009

9. Van Jaarsveld MT, Helleman J, Berns EM and Wiemer EA: MicroRNAs in ovarian cancer biology and therapy resistance. Int J Biochem Cell Biol 42: 1282-1290, 2010.

10. Sugiyama T, Kamura T, Kigawa J, et al: Clinical characteristics of clear cell carcinoma of the ovary: a distinct histologic type with poor prognosis and resistance to platinum-based chemotherapy. Cancer 88: 2584-2589, 2000.

11. Yoshida S, Furukawa N, Haruta S, et al: Theoretical model of treatment strategies for clear cell carcinoma of the ovary: focus on perspectives. Cancer Treat Rev 35: 608-615, 2009.

12. Pectasides D, Pectasides E, Psyrri A and Economopoulos T: Treatment issues in clear cell carcinoma of the ovary: a different entity? Oncologist 11: 1089-1094, 2006.

13. Snowdon J, Zhang X, Childs T, Tron VA and Feilotter H: The microRNA-200 family is upregulated in endometrial carcinoma. PLoS One 6: e22828, 2011.

14. Cui S, Li C, Ema M, Weinstein J and Quaggin SE: Rapid isolation of glomeruli coupled with gene expression profiling identifies downstream targets in Pod1 knockout mice. J Am Soc Nephrol 16: 3247-3255, 2005.

15. American Cancer Society: Global Cancer Facts and Figures 2007. American Cancer Society Inc, Atlanta, GA, 2007.

16. Howlader N, Noone AM, Krapcho M, Neyman N, Aminou R, Altekruse SF, Kosary CL, Ruhl J, Tatalovich Z, Cho H, Mariotto A, Eisner MP, Lewis DR, Chen HS, Feuer EJ, Cronin KA (eds): SEER Cancer Statistics Review: 1975-2008. National Institutes of Health, Bethesda, MD, 2011.

17. Kim MS, In SG, Park OJ, et al: Increased expression of activating transcription factor 3 is related to the biologic behavior of cutaneous squamous cell carcinomas. Hum Pathol 42: 954-959, 2011.

18. Li ZD, Hu XW, Wang YT and Fang J: Apigenin inhibits proliferation of ovarian cancer A2780 cells through Id1. FEBS Lett 583: 1999-2003, 2009.

19. Hai T and Hartman MG: The molecular biology and nomenclature of the activating transcription factor/cAMP responsive element binding family of transcription factors: activating transcription factor proteins and homeostasis. Gene 273: 1-11, 2001.

20. Thompson MR, Xu D and Williams BR: ATF3 transcription factor and its emerging roles in immunity and cancer. J Mol Med (Berl) 87: 1053-1060, 2009.

21. Pelzer AE, Bektic J, Haag P, et al: The expression of transcription factor activating transcription factor 3 in the human prostate and its regulation by androgen in prostate cancer. J Urol 175: 1517-1522, 2006.

22. Janz M, Hummel M, Truss M, et al: Classical Hodgkin lymphoma is characterized by high constitutive expression of activating transcription factor 3 (ATF3), which promotes viability of Hodgkin/Reed-Sternberg cells. Blood 107: 2536-2539, 2006.

23. Bandyopadhyay S, Wang Y,Zhan R, et al: The tumor metastasis suppressor gene Drg-1 down-regulates the expression of activating transcription factor 3 in prostate cancer. Cancer Res 66 : 11983-11990, 2006.

24. Ishiguro T, Nagawa $H$, Naito $M$ and Tsuruo T: Inhibitory effect of ATF3 antisense oligonucleotide on ectopic growth of HT29 human colon cancer cells. Jpn J Cancer Res 91: 833-836, 2000.

25. Hsieh SY, Huang SF, Yu MC, et al: Stathmin1 overexpression associated with polyploidy, tumor-cell invasion, early recurrence, and poor prognosis in human hepatoma. Mol Carcinog 49: 476-487, 2010

26. Lee HS, Lee DC, Park MH, et al: STMN2 is a novel target of beta-catenin/TCF-mediated transcription in human hepatoma cells. Biochem Biophys Res Commun 345: 1059-1067, 2006.

27. Su D, Smith SM, Preti M, et al: Stathmin and tubulin expression and survival of ovarian cancer patients receiving platinum treatment with and without paclitaxel. Cancer 115: 2453-2463, 2009.

28. Ponzielli R, Katz S, Barsyte-Lovejoy D and Penn LZ: Cancer therapeutics: targeting the dark side of Myc. Eur J Cancer 41: 2485-2501, 2005.

29. Lee YY, Kim TJ, Kim MJ, et al: Prognosis of ovarian clear cell carcinoma compared to other histological subtypes: a metaanalysis. Gynecol Oncol 122: 541-547, 2011. 